\title{
FAKTOR-FAKTOR YANG MEMPENGARUHI KEPUASAN KERJA KARYAWAN PT. TRIMEGAH CIPTA MANDIRI
}

\section{FACTORS AFFECTING EMPLOYEE JOB SATISFACTION PT. TRIMEGAH CIPTA MANDIRI}

\author{
Amandin \\ Sekolah Tinggi Ilmu Ekonomi Prabumulih \\ amandinypp50@gmail.com
}

\begin{abstract}
Job satisfaction reflects a person's feelings about his job. The purpose of this study was to determine the factors that affect employee job satisfaction at PT. Trimegah Cipta Mandiri Farm 2 Talang Taling Village, Gelumbang District. The factors in question are the variables of leadership and motivation. This type of research is a survey research with a descriptive quantitative approach. The population is all employees of PT. Trimegah Cipta Mandiri Farm 2 Talang Taling Village, Gelumbang District, the sample was taken 56 people, with a random sampling technique with a saturated sample method. This study uses primary data obtained from respondents' answers in the form of filling out questionnaires, namely data obtained directly from the research object. Data analysis techniques include: instrument testing consisting of validity and reliability tests, classical assumption tests consisting of normality, multicollinearity, and heteroscedasticity tests, multiple linear regression tests and hypothesis testing consisting of the $F$ test, the coefficient of determination test and the t test. The results of the research for the determination test showed an $R$ Square of 0.803. This shows that the leadership and motivation variables simultaneously have an influence of 0.803 or $82.4 \%$ on job satisfaction, while the remaining $19.7 \%$ is the influence of (aspects) or other factors not included in the study, for example training variables, performance etc. While the correlation value $(R)=0.789$. This shows that the variables of leadership and motivation have a very strong correlation to Job Satisfaction.
\end{abstract}

Keywords: Leadership, Motivation and Job Satisfaction

\begin{abstract}
ABSTRAK
Kepuasan kerja mencerminkan perasaan seseorang terhadap pekerjaanya. Tujuan penelitian ini adalah untuk mengetahui faktor-faktor yang mempengaruhi kepuasan kerja karyawan pada PT. Trimegah Cipta Mandiri Farm 2 Desa Talang Taling Kecamatan Gelumbang. Faktor-faktor yang dimaksud yaitu variabel kepemimpinan dan motivasi. Jenis penelitian ini adalah penelitian survey dengan pendekatan kuantitatif deskriptif. Populasi adalah semua karyawan PT. Trimegah Cipta Mandiri Farm 2 Desa Talang Taling Kecamatan Gelumbang, sampel diambil 56 orang, dengan teknik sampling random sampling dengan metode sampel jenuh. Penelitian ini menggunakan data primer yang di dapat dari jawaban responden yang berupa pengisian kuisioner yaitu data yang diperoleh langsung dari obyek penelitian. Teknik analisis data meliputi: uji instrumen terdiri dari uji validitas dan reliabilitas, uji asumsi klasik terdiri dari uji normalitas, multikolinearitas, dan heteroskedastisitas, uji regresi linear berganda serta
\end{abstract}


uji hipotesis yang terdiri dari uji F, uji koefisien determinasi dan uji t. Hasil penelitian untuk uji determinasi menunjukkan R Square sebesar 0,803. Hal ini menunjukan bahwa variabel kepemimpinan dan motivasi secara simultan mempunyai pengaruh sebesar 0,803 atau $82,4 \%$ terhadap kepuasan Kerja, sedangkan sisanya sebesar $19,7 \%$ merupakan pengaruh dari (aspek) atau faktor-faktor lain yang tidak termasuk dalam penelitian misalnya variabel pelatihan, kinerja dll. Sedangkan nilai korelasinya $(R)=$ 0,789. Hal ini menunjukkan bahwa variabel kepemimpinan dan motivasi korelasinya sangat kuat sekali terhadap Kepuasan Kerja.

Kata Kunci: Kepemimpinan, Motivasi dan Kepuasan Kerja

\section{PENDAHULUAN}

Perusahaan perlu menciptakan strategi lingkungan yang kondusif dan memberikan beban kerja sesuai dengan kemampuan untuk meningkatkan kepuasan kerja karyawan. Dewasa ini banyak perusahaan menganggap manusia hanya sebagai salah satu faktor produksi dan menganggap perkembangan teknologi dalam produktivitas jauh lebih penting dibandingkan dengan unsur manusia yang terdapat di dalamnya.

Kepuasan kerja mencerminkan perasaan seseorang terhadap pekerjaanya. Kepuasan kerja adalah keadaan emosional yang menyenangkan atau tidak menyenangkan dimana karyawan memandang pekerjaan mereka (Soegandhi, 2013). Apabila kepuasan kerja karyawan tidak terpenuhi, maka akan terjadi kemerosotan kerja karyawan seperti sering melamun, cepat bosan dan lelah, emosi tidak stabil, sering absen dan melakukan kegiatan yang tidak ada hubungannya dengan pekerjaannya (Arda, 2017). Karyawan yang mendapatkan kepuasan kerja akan lebih semangat dalam menjalankan pekerjaannya.

$\begin{array}{ccc}\text { Salah satu faktor yang } \\ \text { mempengaruhi } & \text { kepuasan } & \text { kerja }\end{array}$ karyawan adalah dengan menumbuhkan kepemimpinan. Kepemimpinan adalah pemberian daya penggerak yang menciptakan kegairahan kerja seseorang agar mereka mau bekerja sama, bekerja efektif dan terintegrasi dengan segala daya upayanya untuk mencapai kepuasan (Soegandhi, 2013). Supriyanto \& Troena (2012) menyatakan karyawan akan kepemimpinan dengan terpenuhinya kepuasan kerja atau rasa keberhasilan dalam menyelesaikan suatu pekerjaan.

Kepuasan kerja cenderung bersifat subjektif karena berkaitan dengan individu masing-masing (Dhania 2010). Kepemimpinan secara umum berkaitan dengan usaha untuk memenuhi semua tujuan sehingga fokus pembahasan dipersempit pada tujuan organisasi supaya dapat merefleksikan perhatian kita pada perilaku yang berkaitan dengan pekerjaan.

Ada beberapa persoalan yang diindikasikan terkait dengan kepuasan kerja karyawan PT. Trimegah Cipta Mandiri Farm 2 Desa Talang Taling Kecamatan Gelumbang. Status karyawan kontrak yang tidak dikuatkan dengan SK menyebabkan kekhawatiran sebagian karyawan akan jaminan dari pihak perusahaan. Persoalan lain yang ditangani juga berkaitan dengan kepuasan kerja adalah perihal tunjangan, kepemimpinan kerjaan dan hubungan dengan pimpinan serta rekan kerja. Tuntutan kerja terhadap kinerja karyawan dirasa tidak cukup sebanding dengan kompensasi yang diberikan perusahaan. Keluhan karyawan akan kondisi pekerjaan dan belum adanya 
kepemimpinan kerja atas hasil kerja kadang sebagai pemicu rendahnya kepemimpinan kerja dari sekian banyak penyebab yang mengakibatkan rendahnya tingkat kepemimpinan. Secara umum disebutkan apabila tenaga dan sarana (kuantitas dan kualitas) tidak sesuai dengan standar yang telah ditetapkan (standard of personels and fasilities), serta jika dana yang tersedia tidak sesuai dengan kebutuhan maka sulitlah diharapkan baiknya mutu pelayanan (Pungkasari, 2013)

Permasalahan yang terjadi yaitu Penurunan kepemimpinan kerja dapat terjadi karena kurang disiplin yang disebabkan oleh turunnya tingkat kepuasan karyawan tersebut. Untuk itu pimpinan perusahaan PT. Trimegah Cipta Mandiri harus memberikan suatu kepemimpinan kepada karyawan sehingga dapat meningkatkan kepuasan kerja karyawan, kepemimpinan dapat berupa pemenuhan kebutuhan fisik, kebutuhan rasa aman dan sebagainya.

Untuk mendapatkan sumber daya manusia yang diharapkan oleh organisasi agar memberikan andil positif terhadap semua kegiatan perusahaan untuk mencapai tujuannya, selain faktor kepemimpinan, motivasi juga dapat mempengaruhi kepuasan kerja karyawan, setiap karyawan diharapkan memiliki motivasi kerja yang tinggi sehingga nantinya akan meningkatkan produktivitas kerja yang tinggi (Susiawan \& Muhid 2015). Motivasi merupakan hal yang sangat penting untuk diperhatikan oleh pihak manajemen bila mereka menginginkan setiap karyawan dapat memberikan kontribusi positif terhadap pencapaian tujuan perusahaan (Murti \& Srimulyani 2013).

\section{METODE PENELITIAN}

$\begin{array}{cc}\text { Desain penelitian } & \text { digunakan } \\ \text { melaksanakan } & \text { penelitian, }\end{array}$ sehingga dapat diperoleh suatu logika baik dalam pengujian hipotesis maupun membuat sebuah kesimpulan. Desain penelitian yang digunakan dalam penelitian ini adalah analisis deskritif yang di bantu dengan metode kuantitatif. Metode kuantitatif adalah metode penelitian berupa angka-angka serta penelitian ini menganalisisnya menggunakan program SPSS.

Objek dan waktu penelitian untuk memperoleh data-data yang dibutuhkan maka untuk mengadakan penelitian pada PT. Trimegah Cipta Mandiri Farm 2 terletak di Desa Talang Taling Kecamatan Gelumbang Kabupaten Muara Enim. Penelitian yang dilakukan ini direncanakan selama 6 (enam) bulan, yakni dari bulan Mei sampai dengan bulan Oktober 2019.

Populasi dalam penelitian ini adalah seluruh karyawan yang bekerja pada PT. Trimegah Cipta Mandiri Farm 2 terletak di Desa Talang Taling Kecamatan Gelumbang Kabupaten Muara Enim yaitu sebanyak 56 orang karyawan.

Adapun sampel dalam penelitian ini adalah di PT. Trimegah Cipta Mandiri Farm 2 terletak di Desa Talang Taling Kecamatan Gelumbang Kabupaten Muara Enim yang diambil sebanyak 56 yang merupakan seluruh karyawan, menggunakan metode sampling sensus. Sampling sensus/jenuh ialah teknik penentuan sampel bila semua anggota populasi digunakan sebagai sampel serta istilah lain dari sampling jenuh adalah sensus, dimana semua anggota populasi dijadikan sampel. Alasan menggunakan sampling jenuh ialah jumlah populasi relatif kecil kurang dari 100 orang.

Analisis yang dapat digunakan agar hasilnya sesuai dengan maksud dan tujuan penelitian yang terdiri dari: Instrumen penelitian adalah alat pada waktu peneliti menggunakan data suatu 
metode pengumpulan data, dalam penelitian ini instrumen yang digunakan berupa angket (kuesioner) yang berisikan pertanyaan yang akan di jawab oleh responden. Dan pengujian terhadap hasil kuesioner digunakan analisis-analisis sebagai berikut: Uji validitas adalah suatu ukuran yang menunjukkan tingkat-tingkat kevalidan atau kesahihan sesuatu instrumen. Teknik yang digunakan untuk uji validitas adalah teknik korelasi Product Moment dari Pearson. Uji reliabilitas adalah indeks yang menunjukkan sejauh mana suatu alat pengukur dapat dipercaya atau dapat diandalkan. Uji reliabilitas ini hanya dilakukan terhadap butir-butir yang valid, dimana butir-butir yang valid diperoleh melalui uji validitas. Teknik yang digunakan untuk uji reliabilitas adalah tehnik Alpha Cronbach.

Metode analisis data menggunakan uji asumsi klasik yang terdiri dari yaitu 1. Uji normalitas dipergunakan untuk menguji apakah sampel yang digunakan memiliki distribusi normal maupun tidak. Regresi linier dalam asumsi ini ditunjukan oleh nilai error $(E)$ yang berdistribusi nornal. 2. Multikolinearitas mempunyai arti terdapat hubungan yang sempurna atau pasti diantara beberapa variabel bebas atau semua variabel bebas diuji model regresi. Uji itu dilakukan untuk tiap-tiap model dengan melihat variance inflation factor (VIF). Apabila nilai VIF melebihi angka 10, maka disimpulkan telah terjadi multikolinearitas sedangkan bila VIF-nya dibawah 10 , maka disimpulkan tidak terjadi multikolinearitas. 3 . Uji Heteroskedastisitas Menurut Setiaji. pengujian ada tidaknya heterokedastisitas bisa dilakukan dengan berbagai macam cara antara lain Uji Grafik, Uji Park, Uji Spearman, Rank Correlation dan Uji LM dan Uji korelasi adalah angka yang menunjukkan arah dan kuatnya hubungan antara dua variabel setelah satu variabel yang di duga dapat berpengaruh dengan variabel lainnya.

\section{Analisa Regresi Berganda}

Adalah analisis yang digunakan untuk mengetahui pengaruh antara beberapa variabel independent $X$ dengan satu variabel dependent $\mathrm{Y}$, yang untuk dinyatakan dengan rumus:

$$
\mathrm{Y}=\mathrm{a}+\mathrm{b} 1 \mathrm{x} 1+\mathrm{b} 2 \mathrm{x} 2+\varepsilon
$$

Dimana:

$\mathrm{Y}=$ Kepuasan Kerja

a $=$ Nilai Konstanta

$\mathrm{b}=$ Koefisien Regresi

$\mathrm{x} 1=$ Kepemimpinan

$\mathrm{x} 2=$ Motivasi

$\varepsilon=$ Nilai Residu

\section{Uji Hipotesis}

\section{Uji Signifikansi Pengaruh Parsial (Uji t)}

Pengujian ini dilakukan untuk mengetahui apakah secara individu variabel independen mempunyai pengaruh secara signifikan terhadap variabel dependen dengan asumsi variabel independen lainnya konstan.

\section{Uji Signifikansi Simultan (Uji f)}

Dalam penelitian ini, uji $\mathrm{f}$ digunakan untuk mengetahui tingkat signifikansi pengaruh variabel-variabel independen secara bersama-sama (simultan) terhadap variabel dependen (Ghozali, 2011:84). Uji koefisien determinasi (Uji R2) dimaksudkan untuk mengetahui tingkat ketepatan baik dalam analisa regresi dimana hal yang ditunjukkan oleh besarnya koefisien determinasi (Uji R2) antara 0 (nol) dan 1 (satu). 


\section{HASIL DAN PEMBAHASAN Uji Instrumen}

Instrumen penelitian adalah alat pada waktu peneliti menggunakan data suatu metode pengumpulan data, dalam penelitian ini instrumen yang digunakan berupa angket (kuesioner) yang berisikan pertanyaan yang akan di jawab oleh responden.

\section{Uji Validitas dan Reliabilitas}

\section{Analisa regresi}

Uji validitas adalah uji statistik digunakan untuk menentukan seberapa valid suatu item pertanyaan. Angka korelasi yang didapatkan dibandingkan dengan $r$ hitung dengan nilai 0,3 . Jika $r$ hitung $>0,3$ maka variabel yang diteliti mempengaruhi hubungan variabel tersebut dikendalikan untuk dibuat tetap keberadaanya adalah valid dan sebaliknya jika $\mathrm{r}$ hitung $<0,3$ maka variabel yang diteliti tidak valid.Uji reliabilitas dinyatakan reliabel apabila nilai cronbach alpha $>0.6$. Seluruh indikator dalam penelitian ini adalah valid dan reliabel.

Tabel 1 Hasil Uji Regresi

\begin{tabular}{|c|c|c|c|c|c|}
\hline \multirow[b]{2}{*}{ Model } & \multicolumn{2}{|c|}{$\begin{array}{l}\text { Unstandardized } \\
\text { Coefficients }\end{array}$} & \multirow{2}{*}{$\begin{array}{c}\begin{array}{c}\text { Standardized } \\
\text { Coefficients }\end{array} \\
\text { Beta } \\
\end{array}$} & \multirow[t]{2}{*}{$\mathbf{t}$} & \multirow[t]{2}{*}{ Sig. } \\
\hline & B & $\begin{array}{l}\text { Std. } \\
\text { Error }\end{array}$ & & & \\
\hline 1 (Constant) & 47.328 & 11.574 & & 4.231 & .000 \\
\hline $\begin{array}{l}\text { Kepemimpinan } \\
\text { (X1) }\end{array}$ & .648 & .754 & .532 & 2.226 & .014 \\
\hline Motivasi (X2) & .483 & .526 & .661 & 1.631 & .016 \\
\hline
\end{tabular}

Sumber : Data Olahan (2020)

Berdasarkan tabel 1 di atas yang diperoleh dari hasil uji regresi maka estimasi fungsi regresi yang diperoleh adalah :

$\mathrm{Y}=47,328+0,648 \mathrm{X} 1+0,483 \mathrm{X} 2+$ $11,574 \mathrm{e}$

Persamaan regresi tersebut dapat dijelaskan sebagai berikut :

1. Nilai konstanta $=47.328$ dengan tanda positif yang merupakan nilai konstanta dimana diartikan bahwa jika variabel-variabel independen yaitu Kepemimpinan dan motivasi diasumsikan dengan nilai konstan, maka variabel dependen yaitu kepuasan kerja akan naik sebesar 47.328 .

2. Nilai koefisien regresi X1 sebesar 0 , 648 artinya untuk setiap kenaikan 1 skor variabel Kepemimpinan (X1) akan menaikkan skor Kepuasan Kerja (Y) sebesar 0, 648.

3. Nilai koefisien regresi $\mathrm{X} 2$ sebesar 0,483 artinya untuk setiap kenaikan 1 skor variabel motivasi (X2) akan menaikkan skor kepuasan kerja (Y) sebesar 0,483.

\section{Uji Hipotesis}

\begin{tabular}{lr}
\multicolumn{2}{c}{ Pengujian hipotesis dalam } \\
penelitian bertujuan untuk \\
membuktikan pengaruh Kepemimpinan,
\end{tabular}


motivasi terhadap Kepuasan Kerja pada karyawan PT. Trimegah Cipta Mandiri Farm 2 Desa Talang Taling Kecamatan Gelumbang. Adapun tabel hasil uji $\mathrm{f}$ dan uji t disajikan sebagai berikut:

\section{Uji F}

Pengujian pengaruh variabel bebas secara bersama-sama terhadap variabel terikat dilakukan dengan menggunakan uji F. Hasil perhitungan statistik menunjukan nilai Fhitung = 13,575 dengan signifikansi sebesar
$0,001<0,05$ Dengan nilai signifikansi dibawah 0,05 menunjukan bahwa secara bersama-sama Kepemimpinan dan motivasi mempunyai pengaruh yang positif dan signifikan terhadap Kepuasan Kerja, hal ini berarti hipotesis diterima. Hasil perhitungan regresi secara bersama-sama diperoleh pada tabel 4.12 Berikut :

Tabel 2 Hasil Analisis Regresi Secara Bersama-sama

\begin{tabular}{|c|c|c|c|c|c|c|}
\hline \multicolumn{2}{|c|}{ Model } & \multirow{2}{*}{$\frac{\text { Sum of Squares }}{1280.009}$} & \multirow{2}{*}{$\frac{\mathrm{df}}{4}$} & \multirow{2}{*}{$\begin{array}{c}\text { Mean } \\
\text { Square }\end{array}$} & \multirow{2}{*}{$\frac{F}{13.575}$} & \multirow{2}{*}{$\frac{\text { Sig. }}{.001^{\mathrm{a}}}$} \\
\hline 1 & Regression & & & & & \\
\hline & Residual & 2672.951 & 95 & 26.136 & & \\
\hline & Total & 3952.960 & 99 & & & \\
\hline
\end{tabular}

Sumber : Data Olahan (2020)

\section{Uji t (secara parsial)}

Tabel 3. Uji T

\begin{tabular}{|c|c|c|c|c|c|c|}
\hline \multirow{2}{*}{\multicolumn{2}{|c|}{ Model }} & \multicolumn{2}{|c|}{$\begin{array}{l}\text { Unstandardized } \\
\text { Coefficients }\end{array}$} & \multirow{2}{*}{$\begin{array}{c}\text { Standardized } \\
\text { Coefficients }\end{array}$} & \multirow[t]{2}{*}{$\mathrm{t}$} & \multirow[t]{2}{*}{ Sig. } \\
\hline & & B & Std. Error & & & \\
\hline \multirow[t]{3}{*}{1} & (Constant) & 47.328 & 11.574 & & 4.231 & .00 \\
\hline & $\begin{array}{l}\text { Kepemimpina } \\
\text { kerja }(\mathrm{X} 1)\end{array}$ & .648 & .754 & .532 & 2.226 & .01 \\
\hline & Motivasi (X2) & .483 & .526 & .661 & 1.631 & .0 \\
\hline
\end{tabular}

Sumber : Data Olahan (2020)

Uji parsial digunakan untuk mengetahui pengaruh masing-masing variabel independen terhadap variabel dependen dengan yang diuji. Diketahui untuk pengaruh variabel $\mathrm{X} 1$ terhadap $\mathrm{Y}$ adalah nilai $t$ hitung $2.226>$ nilai $t$ tabel 2.006. berdasarkan analisis pengaruh variabel independen Kepemimpinan (X1) terhadap variabel dependen Kepuasan Kerja berpengaruh positif, dapat dilihat dari nilai $\mathrm{t}$ hitung lebih besar dari nilai $t$ tabel, maka $\mathrm{H} 1$ diterima Kepemimpinan terhadap Kepuasan Kerja. Diketahui untuk pengaruh variabel X2 terhadap $\mathrm{Y}$ adalah nilai t hitung $1.631>$ nilai $\mathrm{t}$ tabel 2.006 . berdasarkan analisis pengaruh variabel independen motivasi (X2) terhadap variabel dependen Kepuasan Kerja berpengaruh positif, dapat dilihat dari 
nilai $\mathrm{t}$ hitung lebih kecil dari nilai $\mathrm{t}$ tabel, maka H2 diterima berarti terdapat pengaruh antara kepemimpinan terhadap Kepuasan Kerja

berarti terdapat pengaruh antara Diketahui untuk pengaruh variabel X2 terhadap Y adalah nilai t hitung 1.631 > nilai t tabel 2.006. berdasarkan analisis pengaruh variabel independen motivasi (X2) terhadap variabel dependen Kepuasan Kerja berpengaruh positif, dapat dilihat dari nilai $\mathrm{t}$ hitung lebih kecil dari nilai t tabel, maka $\mathrm{H} 2$ diterima berarti terdapat pengaruh antara kepemimpinan terhadap Kepuasan Kerja

\section{Koefisien Determinasi}

Nilai koefisien determinasi ditentukan dengan nilai adjusted $R$ square. Hasil dari pengolahan data yang menggunakan bantuan program SPSS , juga menghasilkan output berupa tabel koefisien model summary. Analisis koefisien determinasi ini menghasilkan gambaran seberapa signifikan pengaruh secara simultan variabel indevenden yaitu kepemimpinan kerja dan motivasi terhadap Kepuasan Kerja karyawan PT. Trimegah Cipta Mandiri Farm 2 Desa Talang Taling Kecamatan Gelumbang seperti terlihat pada Tabel 5 berikut.

Tabel 4 Koefisien Determinasi

\begin{tabular}{|c|c|c|c|c|}
\hline Model & $\mathrm{R}$ & R Square & $\begin{array}{l}\text { Adjusted R } \\
\text { Square }\end{array}$ & $\begin{array}{l}\text { Std. Error of the } \\
\text { Estimate }\end{array}$ \\
\hline 1 & $\begin{array}{r}.78 \\
9^{\mathrm{a}}\end{array}$ & .803 & .745 & 5.304 \\
\hline
\end{tabular}

Sumber : Data Olahan (2020)

Dari output model summary didapatkan Tabel 14 determinasi di atas yang memberikan $R$ Square sebesar 0,803 . Hal ini menunjukan bahwa variabel kepemimpinan dan motivasi secara simultan mempunyai pengaruh sebesar 0,803 atau $82,4 \%$ terhadap kepuasan Kerja, sedangkan sisanya sebesar 19,7\% merupakan pengaruh dari (aspek) atau faktor-faktor lain yang tidak termasuk dalam penelitian misalnya variabel pelatihan, kinerja dll. Sedangkan nilai korelasinya $(\mathrm{R})=$ 0,789 . Hal ini menunjukkan bahwa variabel kepemimpinan dan motivasi korelasinya sangat kuat sekali terhadap Kepuasan Kerja.

\section{Pembahasan}

Untuk menguji keberartian
model regresi untuk masing masing variabel secara parsial dapat diperoleh dengan menggunakan uji t. Berikut akan dijelaskan pengujian masing-masing variabel secara parsial :

1. Variabel Kepemimpinan (X1)

Hasil pengujian diperoleh nilai $\mathrm{t}$ untuk variabel tampilan Kepemimpinan menunjukan nilai $\mathrm{t}=$ 2.226 dan motivasi nilai $\mathrm{t}=2,006$. Dengan nilai signifikansi sebesar dengan nilai signifikansi sebesar $0,052<0,05$ dan dengan nilai dibawah 0,05 tersebut menunjukan bahwa Kepemimpinan dan motivasi memiliki pengaruh yang signifikansi terhadap Kepuasan Kerja. Hal ini berarti Hipotesis diterima.

2. Variabel Motivasi (X2)

Diketahui untuk pengaruh variabel $\mathrm{X} 2$ terhadap $\mathrm{Y}$ adalah nilai $\mathrm{t}$ hitung $1.631>$ nilai $t$ tabel 2,006, berdasarkan analisis terhadap pengaruh variabel independen motivasi (X2) terhadap variabel dependen Kepuasan Kerja berpengaruh positif, dapat dilihat dari nilai t hitung lebih kecil dari nilai $t$ tabel, maka $\mathrm{H} 2$ diterima berarti terdapat pengaruh antara motivasi terhadap Kepuasan Kerja

Arah koefisien regresi positif berarti bahwa Kepemimpinan memiliki pengaruh positif yang signifikan terhadap Kepuasan Kerja. Semakin baik kepemimpinan dan motivasi yang ada 
akan semakin tinggi pula Kepuasan Kerja, sebaliknya semakin tidak baik kepemimpinan yang ada semakin rendah pula kepuasan Kerja. Hasil analisis kuantitatif menunjukkan bahwa variabel kepemimpinan dan motivasi mempunyai pengaruh yang positif terhadap kepuasan Kerja pada PT. Trimegah Cipta Mandiri Farm 2 Desa Talang Taling Kecamatan Gelumbang Berdasarkan hasil analisis, kepemimpinan dan motivasi terhadap Kepuasan Kerja pada PT. Trimegah Cipta Mandiri Farm 2 Desa Talang Taling Kecamatan Gelumbang terhadap Kepemimpinan dan motivasi, hal ini harus terus dipertahankan kepuasan kerja PT. Trimegah Cipta Mandiri Farm 2 Desa Talang Taling Kecamatan Gelumbang dapat lebih baik lagi, semakin tinggi kepemimpinan dan motivasi yang diperlihatkan oleh PT. Trimegah Cipta Mandiri Farm 2 Desa Talang Taling Kecamatan Gelumbang maka akan mempengaruhi Kepuasan Kerja.

Berdasarkan analisa regresi diperoleh koefisien determinasi (RSquare) yang diperoleh dari kepemimpinan dan motivasi terhadap kepuasan Kerja adalah sebesar 0,803. Hal ini menunjukkan bahwa peningkatan kepemimpinan dan motivasi terhadap kepuasan Kerja adalah sebesar $80,3 \% \%$ artinya kepemimpinan dan motivasi memberikan sumbangan efektif sebesar $80,3 \%$ dalam meningkatkan Kepuasan Kerja, sedangkan sisanya 19,7\% dipengaruhi faktor faktor lain yang tidak diteliti dalam penelitian ini, seperti pelatihan, kinerja dan lain-lain

\section{PENUTUP \\ Kesimpulan}

Berdasarkan hasil analisis yang telah dilakukan pada penelitian ini diperoleh hasil uji, maka dapat diambil beberapa kesimpulan sebagai berikut :

1. Diketahui untuk pengaruh variabel kepemimpinan (X1) terhadap Y, hasil pengujian diperoleh nilai $t$ untuk variabel tampilan kepemimpinan menunjukan nilai $\mathrm{t}$ hitung $=5.469>$ nilai $\mathrm{t}$ tabel 2.006 . Dengan nilai signifikansi sebesar sebesar $0,000<0,05$ dan dengan nilai dibawah 0,005 tersebut menunjukan bahwa kepemimpinan memiliki pengaruh yang signifikansi terhadap kepuasan kerja. Semakin baik kepemimpinan yang ada akan semakin tinggi pula kepuasan kerja, sebaliknya semakin tidak baik kepemimpinan yang ada semakin rendah pula kepuasan kerja.

2. Diketahui untuk pengaruh variabel motivasi (X2) terhadap $\mathrm{Y}$ adalah nilai $\mathrm{t}$ hitung $2.023>$ nilai $\mathrm{t}$ tabel 2.006. Dengan nilai signifikansi sebesar sebesar $0,000<0,05$ dan dengan nilai dibawah 0,005 tersebut menunjukkan bahwa motivasi memiliki pengaruh yang signifikansi terhadap kepuasan kerja. Semakin baik motivasi yang ada akan semakin tinggi pula kepuasan kerja, sebaliknya semakin tidak baik motivasi yang ada semakin rendah pula kepuasan kerja.

3. Pengujian pengaruh variabel bebas secara bersama-sama terhadap variabel terikat dilakukan dengan menggunakan uji F. Hasil perhitungan statistik menunjukkan nilai Fhitung $=509,604>$ Ftabel $=$ 3.780 dan dengan nilai signifikansi sebesar $0,00<0,05$ Dengan nilai signifikansi dibawah 0,05 menunjukan bahwa secara bersamasama kepemimpinan, motivasi mempunyai pengaruh yang positif dan signifikan terhadap Kepuasan kerja pada PT. Trimegah Cipta Mandiri. 


\section{Saran}

Berdasarkan hasil penelitian
maka saran-saran yang dapat
disampaikan sebagai berikut:

1. Untuk pihak manajemen yang ada di PT. Trimegah Cipta Mandiri, diharapkan untuk lebih memperhatikan kondisi perusahaan saat ini untuk lebih melakukan pengawasan, kemudian diharapkan untuk membuka kesempatan promosi bagi karyawan sehingga mereka lebih termotivasi lagi untuk bekerja dengan lebih baik dan dengan kondisi yang lebih baik pula.

2. Untuk karyawan yang bekerja di perusahaan yang ada di PT. Trimegah Cipta Mandiri, diharapkan untuk lebih berpikiran jauh kedepan untuk masa depan masing-masing, karena walaupun lingkungan kerja dan rekan kerja sangat baik dan mendukung, namun esensi dari kita bekerja harus jauh lebih maju dari hanya sekadar mendapatkan penghasilan yang cukup dan lebih mementingkan kebutuhan sosial saja. Namun motivasi yang dibawa oleh tiap individu harus meliputi karir dan kehidupan di masa depan yang lebih baik, sehingga pelatihan mengenai goal setting dan peningkatan ketrampilan sangat diperlukan oleh setiap karyawan.

3. Untuk penelitian lebih lanjut, agar dapat ditambahkan pula variabel baru untuk lebih melengkapi hasil dari penelitian ini dan lebih mengeksplorasi fenomena yang ada, hal ini dirasakan oleh penulis dimana pada saat wawancara konfirmasi hasil penelitian

4. Pada penelitian selanjutnya diharapkan dapat mengkaji lebih mendalam variabel kepemimpinan, motivasi dan Kepuasan Kerja Karyawan pada variabel lainnya serta dapat menambahkan variabel lain agar supaya model konseptual untuk peneliti kedepan akan semakin kompleks dan dapat memberikan kontribusi bagi pengembangan ilmu.

\section{DAFTAR PUSTAKA}

Arda, M. (2017). Pengaruh Kepuasan Kerja Dan Disiplin Kerja Terhadap Kinerja Karyawan Pada Bank Rakyat Indonesia Cabang Putri Hijau Medan. Jurnal Ilmiah Manajemen dan Bisnis, 18(1), 45-60.

Dhania, D. R. (2010). Pengaruh Stres Kerja, Beban Kerja, terhadap kepuasan Kerja (studi pada medical representatif di Kota Kudus). Jurnal Psikologi: PITUTUR, 1(1), 15-23.

Murti, H., \& Srimulyani, V. A. (2013). Pengaruh Motivasi Terhadap Kinerja Pegawai Dengan Variabel Pemediasi Kepuasaan Kerja Pada PDAM Kota Madiun. JRMA $\mid$ Jurnal Riset Manajemen dan Akuntansi, 1(1), 10-17.

Pungkasari, R. (2013). Hubungan Pengetahuan Dan Sikap Tenaga Kesehatan Dengan Mutu Pelayanan Pada Pasien Rawat Inap Rumah Sakit Umum Daerah Di Kabupaten Boyolali(Doctoral dissertation, UNS (Sebelas Maret University)

Susiawan, S., \& Muhid, A. (2015). Kepemimpinantransformasional, kepuasan kerja dan komitmen organisasi. Persona: Jurnal Psikologi Indonesia, 4(03). 
Soegandhi, V. M. (2013). Pengaruh kepuasan kerja dan loyalitas kerja terhadap organizational citizenship behavior pada karyawan PT. Surya Timur Sakti Jatim. Agora, 1(1), 808-819.

Supriyanto, A. S., \& Troena, E. A. (2012). Pengaruh Kecerdasan Emosional dan Kecerdasan Spiritual terhadap Kepemimpinan Transformasional, Kepuasan Kerja dan Kinerja Manajer (Studi di Bank Syari'ah Kota Malang)'. Jurnal Aplikasi Manajemen, 10(4), 693-617. 